\title{
Evaluating the relationship between socially (dis)advantaged neighbourhoods and customer satisfaction of bus service in London, U.K.
}

For Citation please use : Grisé, E. \& El-Geneidy, A. (2017). Evaluating the relationship between

\author{
Ahmed El-Geneidy \\ School of Urban Planning \\ McGill University \\ Suite 400, 815 Sherbrooke St. W. \\ Montréal, Québec, H3A 0C2 \\ Canada \\ Tel.: 514-398-4058 \\ Fax: 514-398-8376 \\ E-mail: ahmed.elgeneidy@mcgill.ca
} socially (dis)advantaged neighbourhoods and customer satisfaction of bus service in London, U.K. Transport Geography, 58, 166-175. 


\section{ABSTRACT}

4 Affordable and efficient urban public transport is important for the development of a sustainable 5 urban environment. Making sure public transport users are satisfied with the service is a goal many 6 public transport agencies are trying to achieve. Customer satisfaction surveys are often used to 7 monitor customer perceptions of service quality and to determine the relative influence of service 8 attributes on a customer's overall assessment of the service. This study presents a new method to 9 spatially evaluate customer satisfaction survey data through examining satisfaction with bus 10 service across neighbourhoods of varying levels of socio-economic status (SES). Using customer 11 satisfaction survey data collected by Transport for London between 2010 and 2015, multi-level 12 regression modeling is used to estimate the relationship between overall satisfaction and social 13 deprivation of the area in which bus routes were operating. The results indicate lower levels of 14 satisfaction along routes serving low SES neighbourhoods, which appears to be attributed to (1) 15 low satisfaction with service characteristics related to an individual's experience and quality of the 16 bus and (2) conditions of the bus stop and shelter. Findings from this paper shows the importance 17 of including cleanliness and bus internal quality as one of the performance indicators when 18 contracting bus services, to ensure that all customers receive the same quality of service in the 19 region regardless of their SES. 


\section{INTRODUCTION}

An affordable and efficient urban public transport system is essential to the economic development of a city and the social quality of life of its residents. The success of a public transport agency largely depends on the number of satisfied passengers using the system who will continue to use it in the future (de Oña, de Oña et al. 2013). As a means of attracting and retaining ridership levels, public transport agencies have placed increasing importance on improving service quality (de Oña, de Oña et al. 2013). Service quality is related to a series of attributes describing the public transport service, such as reliability, accessibility, safety and travel time. While most public transport agencies have internal measurements of performance such as operating efficiency, on-time performance and service quality, the customer's point of view is particularly relevant for evaluating performance (Eboli and Mazzulla 2011), as customers are the most important judges of service quality (Berry, Zeithaml et al. 1990, Diab, Badami et al. 2015). Nevertheless it is important to note that some disconnect might exists between customers' perceptions of service and agencies' service delivery (Diab, Badami et al. 2015).

To monitor customer perceptions of public transport service quality, customer satisfaction surveys are used to understand passengers' perceptions about each attribute characterizing the service, and their relative influence on the global assessment of service (de Oña, de Oña et al. 2013). In order to design appropriate transport strategies that can improve customer satisfactions with service quality, considerable research has been conducted to identify which attributes have the strongest influence on the overall assessment of service quality (Hensher, Stopher et al. 2003, de Oña, de Oña et al. 2013, Eboli and Mazzulla 2015).

High levels of customer satisfaction do not necessarily mean that the public transport network is an objectively better system, rather satisfaction is a relative concept that is based on expectations (Friman and Fellesson 2009). Moreover, variations in satisfaction with bus service in a region can be used to assess differences in the levels of service being delivered to every neighborhood especially in regions where multiple transit operators are providing these services. This study presents a new method to spatially evaluate customer satisfaction survey data through examining satisfaction with bus service across neighbourhoods of varying levels of socioeconomic status (SES). The central question driving this research is whether there are discernable differences in the quality of bus service provided in areas of higher and lower SES in the Greater London Area, UK. This study evaluates the relationship between levels of customer satisfaction among users of bus service and the level of social deprivation of the neighbourhood the route is serving, using data collected from a large-scale bus customer satisfaction survey conducted by Transport for London (TfL). Results of this study are intended to provide planners, engineers and policy makers with a better understanding of how public transit customers perceive service across a network (spatially) in order to identify areas of improvement to ensure that quality service is experienced by all customers across all neighborhoods in a region. To our knowledge, this is the first paper to spatially model customer satisfaction among bus users and combine that with an equity analysis at a neighborhood level to provide guidance for a better public policy.

The paper begins with a review of the relevant literature related to indicators of service quality and customer satisfaction. The next section introduces the study area and data used. This is followed by an exploratory analysis of the relationship between social deprivation and overall satisfaction and satisfaction with factors of relevant service attributes which are derived using Principle Component Analysis. Next, multi-level regression models are constructed to predict satisfaction. Lastly, the paper concludes with a discussion of the findings. 


\section{LITERATURE REVIEW}

The rising cost of providing a high quality public transport service generates conflicting goals for public transport agencies who must balance economic efficiency and ridership targets with service need and equity (Murray and Davis 2001), which can be viewed as opposing public transport goals. Walker (2008) classifies these opposing goals as first a largely economically driven goal for increased patronage and second a goal for increased equitable outcomes, or increased social inclusion, by increasing coverage of service for existing public transport users regardless of the implications for ridership or profitability of the service. Equity in public transport research is largely related to the distibution of transport supply, and the corresponding benefits that the transport system offers to different populations (Jones and Lucas 2012). There have been several studies assessing the distribution of public transport service in a region (Martens, Golub et al. 2012, Foth, Manaugh et al. 2013, Legrain, Buliung et al. 2016). These studies use accessibility as a performance measure, referring to the ease of reaching destinations with public transport (Hansen 1959). While these studies evaluate equity from the public transport provision side, there appears to be a gap in the literature related to assessing the quality of service provided across a region, particularly the assessment of customer perceptions of service being provided across a network.

Customer satisfaction is a subjectively measured quality of service indicator, which is perceived as an important determinant of a users' travel demand (Prioni and Hensher 2000). Customer satisfaction generally results from a commuter's reaction to his or her experience with the service and to what extent it meets their needs and/or expectations (Grigoroudis and Siskos 2009). Improvements in passengers' satisfaction is generally associated with higher levels of consumer loyalty (Olsen 2007), where loyal customers are more likely to continue to use the service. A customer's satisfaction with public transport is derived from a range of factors, from objective performance characteristics to personal characteristics including socio-demographics, personal preferences and habits (Diab, Badami et al. 2015). Understanding passengers' perception of service and what makes a satisfied public transport user has been the subject of a considerable amount of research (Andreassen 1995, Friman 2004, Tyrinopoulos and Antoniou 2008). Furthermore, analysis of customer satisfaction data has been applied to identify the relative importance of service attributes, and their influence on a users' overall assessment of the service (Hensher, Stopher et al. 2003, de Oña, de Oña et al. 2013, Eboli and Mazzulla 2015). However, research indicates that the perception of quality and the relative importance of service attributes vary among groups of users (dell'Olio, Ibeas et al. 2010).

Acknowledging that there are different groups who use transit is important in understanding the causes of satisfaction and how individual needs and expectations vary (Beirão and Cabral 2007, dell'Olio, Ibeas et al. 2010, Bordagaray, dell'Olio et al. 2014). This finding has given way for studies to examine customer satisfaction data among different types of users. van Lierop and El-Geneidy (2016) used a transit market segmentation approach to examine the causes of satisfaction and loyalty for each segment of riders, to derive specific strategies for each type of transit user. Tyrinopoulos and Antoniou (2008) segmented respondents by their sex to evaluate differences among perceptions and the relative importance of service attributes between these groups. (De Ona, de Oña et al. 2015) applied a classification and regression tree approach to analyze satisfaction data of a suburban rail service among categorized types of users (i.e. the day of travel, frequency of use, and time of travel during the day), and found preferences and importance of service aspects to vary among these different groups of users. Lastly, Verbich and El-Geneidy (2016) modeled satisfaction of public transport passengers with various 
encumberments or physical disabilities, to understand how these users value different service attributes of the bus compared to other types of users. Despite the recent work being conducted on different groups of public transport users, the literature available on customer perceptions of service among segmented populations remains limited. Furthermore, to the author's knowledge, no studies have attempted to spatially explore the variation in customer satisfaction levels. This study presents a new method of examining data from a large-scale customer satisfaction survey, to understand how passengers perceive the quality of public transport service across a bus network that is serving different neighborhoods with high variation in socioeconomic status.

\section{ANALYSIS}

\section{Study Area and Survey Overview}

Public transport service in the Greater London, UK area is provided by Transport for London (TfL), and is managed by London Buses. TfL manages one of the worlds' largest bus networks, with over 675 bus routes, and is ranked as the top city in the world for its size, frequency, reliability and accessibility (Begg 2013). London Buses are operated under contracts with private operators, where contracts are awarded on a competitive basis. Minimum performance standards with respect to the quality of service are set, and contract payments are related to the mileage operated and service reliability, while contracts can be terminated as a result of poor performance (Transport for London 2015). Furthermore, London Buses have been conducting customer satisfaction surveys since 1997 in order to monitor customer satisfaction with the quality of services provided and to identify areas for improvement (Transport for London 2015). Surveys are conducted through face-to-face interviews with passengers alighting from buses. After a person alights the bus they are approached by a TfL representative who conduct the survey with them. Survey questions are related to the bus journey that a person just made, and include questions related to the presence of a bus shelter available at the bus stop they boarded at, their journey time in minutes and type of fare payment used. Customers are then asked a series of satisfaction questions, ranging from their overall satisfaction with their bus journey to satisfaction with specific elements of their journey, such as information provided on the bus, safety and security, service reliability and waiting time. For customers that were unsatisfied with an element of their trip (rating of 6 or less), interviewers were instructed to ask follow up questions regarding their low satisfaction with that service attribute. Furthermore, survey respondents were asked for a range of personal characteristics, such as their gender, ethnicity, age and familiarity with that particular bus trip.

The initial dataset consisted of 65,506 survey responses collected between 2010 and 2015 . We included only respondents within the ages of 20 and 64 years old, which reduced the dataset to 48,344 responses. We then limited responses to individuals who were taking the bus for a commuting purpose (categorized as to/from work, employer's business or education and personal business), which reduced the dataset to 28,619 responses. Responses were limited to adults commuting for the purpose of work or education as these trips represents the majority of the users and to focus the analysis on individuals' with regular travel behavior, other groups not included have special needs and require a different approach in analysis. Further, we removed respondents who specified a disability, or riders who were encumbered with any of the following items on their bus trip: suitcase/heavy luggage and/or large awkward item, shopping bags and/or shopping trolley, or a small child/baby in arms and/or a baby buggy/pushchair/pram. 'Disabled riders' and 'encumbered riders' were excluded from this analysis as a previous study found that riders with encumbrances or disabilities value different features of the bus service when compared to other 
groups of riders (Verbich and El-Geneidy 2016). Finally, 17,516 individual responses remained for further analysis after the removal of surveys with missing responses to questions of interest.

The relationship between customer satisfaction and social deprivation was first explored by evaluating the average overall satisfaction scores and the social deprivation indicator of each route. Overall satisfaction was evaluated by asking survey respondents: "Thinking about this particular bus journey you have just made, starting at the bus stop, how satisfied are you on a scale of 0 to 10 (where 10 is extremely satisfied and 0 is extremely dissatisfied) with the overall service you experienced today?" These surveys were conducted between the years 2010 and 2015, and were administered by trained interviewers as intercept interviews as passengers alighted a bus operating in the Greater London Area. Average satisfaction for each bus route was calculated from individual survey responses, if more than 30 complete survey responses were available for that route to ensure stability in the variance between responses at the route level. This resulted in 198 routes with which to evaluate average satisfaction at the route level. Next, we develop an indicator of the level of social deprivation for the neighbourhood the route serves.

\section{Social Deprivation Indicator}

The indicator was developed to measure the level of social deprivation of the area in which every bus route operated in. The indicator is comprised of the following four demographic variables and data sources:

- Percent of the population born outside of the United Kingdom (Census, 2011)

- Percent of residents that are unemployed and actively seeking work, excluding students (Census 2011)

- Total median annual household income (Greater London Authority, 2011)

- Percent of the population living in deprived households reliant on means tested benefits (Department for Communities and Local Government, 2011)

These variables have commonly been used to identify socially vulnerable populations in the UK (Church, Frost et al. 2000, Wu and Hine 2003). For this study, the variables were selected to best identify neighbourhoods with high proportions of individuals of higher social disadvantage in the UK. However, through the application of aggregate census data, it is important to cautiously interpret the findings, as not everyone who is socially deprived necessarily lives in an area classified as more socially deprived, or similarly not everyone who lives in a more socially deprived area is deprived (Townsend, Phillimore et al. 1998).

In order to generate an index from these four variables, each of the variables was standardized, equally weighted and summed to create the social deprivation indicator value, which was similar to a method employed by(Sánchez-Cantalejo, Ocana-Riola et al. 2008, Foth, Manaugh et al. 2013, El-Geneidy, Buliung et al. 2016). Note, median income was inverted to capture the relation between social deprivation and income. The unit of analysis is the Middle Super Output Area (MSOA) level (equivalent to North American census tract), which are generally comprised of a population between 5,000 and 15,000, representing between 2,000 and 6,000 households (Office for National Statistics 2015). There are 982 MSOA units within the Greater London Area. Using the data described above for each MSOA, the social deprivation indicator was calculated for each MSOA. Using this approach, we identified socially disadvantaged areas that are predominantly characterized by foreign-born residents, high unemployment, low income, and households dependent on social assistance.

To determine the level of social deprivation associated with each bus route, a network of all TfL bus routes was created within a Geographic Information System and the bus routes were 
intersected with the MSOAs. In most cases the bus route intersected multiple MSOAs, so in that case a weighted average of each MSOAs' deprivation indicator was used based on the proportional length of the route segment within the MSOA to the total route length. Although London has become more socially segregated at the micro scale (Hamnett 2003) and variation in social deprivation may exist along the bus route, applying a weighted average provides an estimate of the of the overall SES of the neighbourhood the route is serving.

After calculating the social deprivation indicator of each route we mapped the average overall satisfaction and provide a visual comparison with the route-level social indicator, as shown in Figure 1. By examining Figure 1, a pattern appears to emerge between social deprivation and route-level satisfaction. Namely, a strong inverse relationship between overall customer satisfaction and social deprivation can be seen in Eastern London, specifically adjacent to the River Thames. North of the River Thames, we see bus routes with low overall satisfaction, which are operating in boroughs of higher social deprivation, while we see an opposite relationship in eastern boroughs located south of the River Thames. To ascertain the inverse relationship between routelevel satisfaction and social deprivation, we applied further statistical methods that are presented and discussed below.

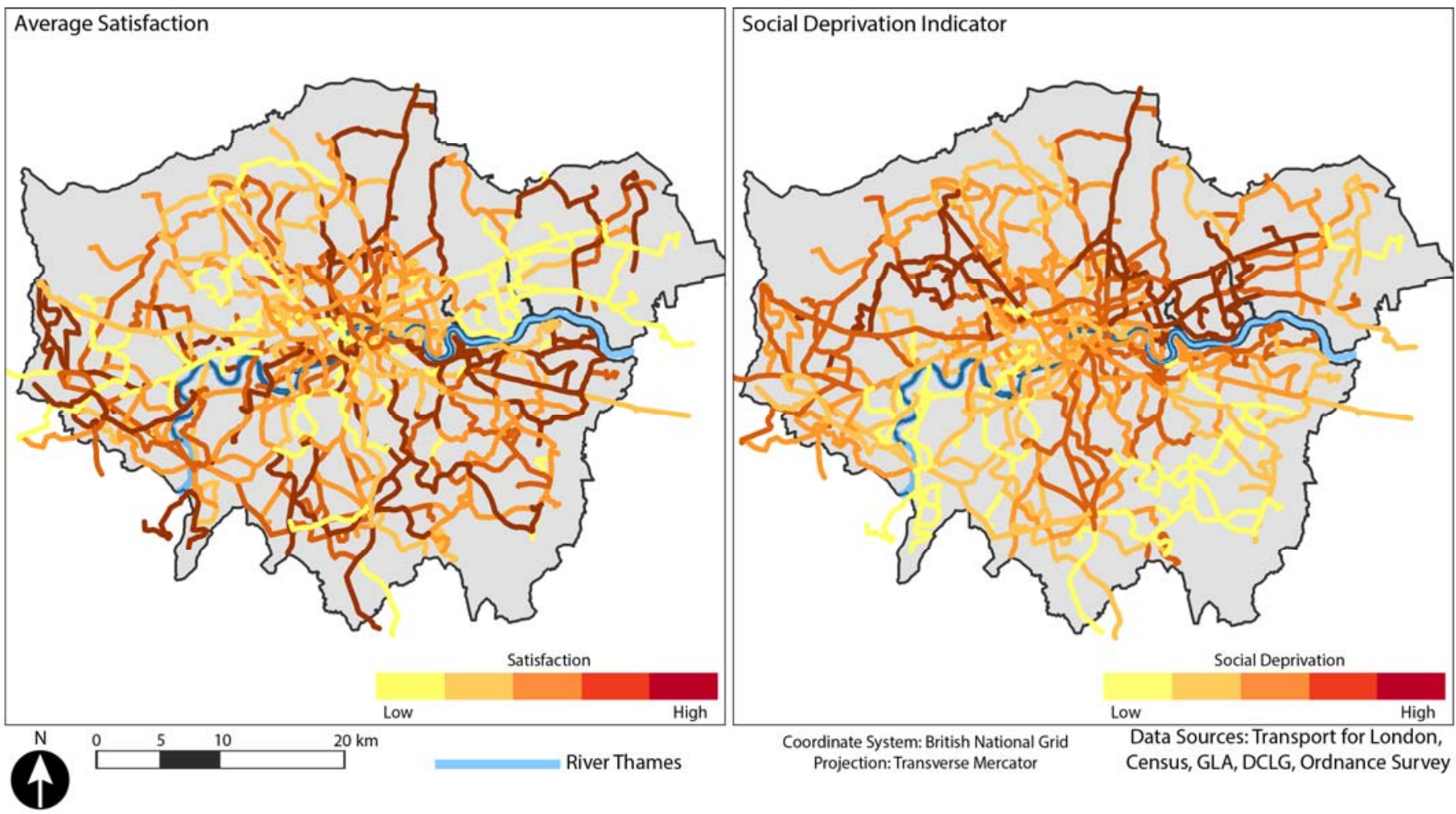

FIGURE 1 Average overall satisfaction of each bus route and level of neighbourhood social deprivation of bus routes.

\section{Route Level Analysis}

21 A scatterplot of the relationship between average route satisfaction and social deprivation is displayed in Figure 2, while four scatterplots present the relationship between average overall route satisfaction and each of the variables that comprise the social deprivation indicator in Figure 3. The main finding from these plots is that route-level satisfaction decreases in more socially deprived neighborhoods. 


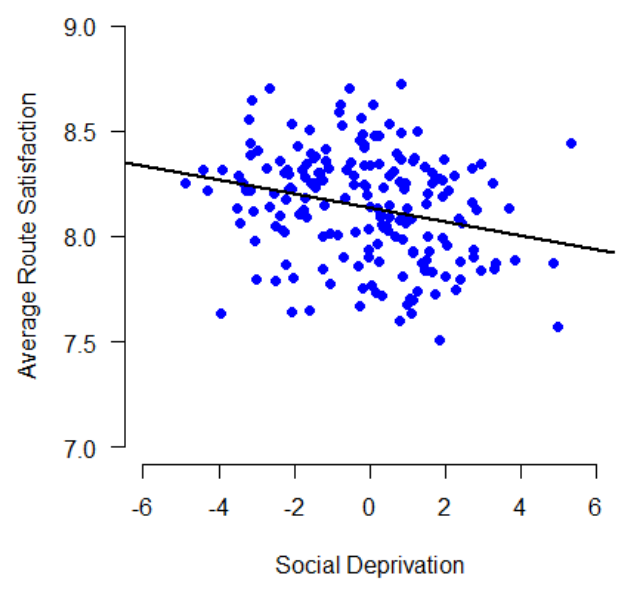

FIGURE 2 Plot of the relationship between average overall bus route satisfaction and the social deprivation indicator (statistically significant at $99 \%$ level).
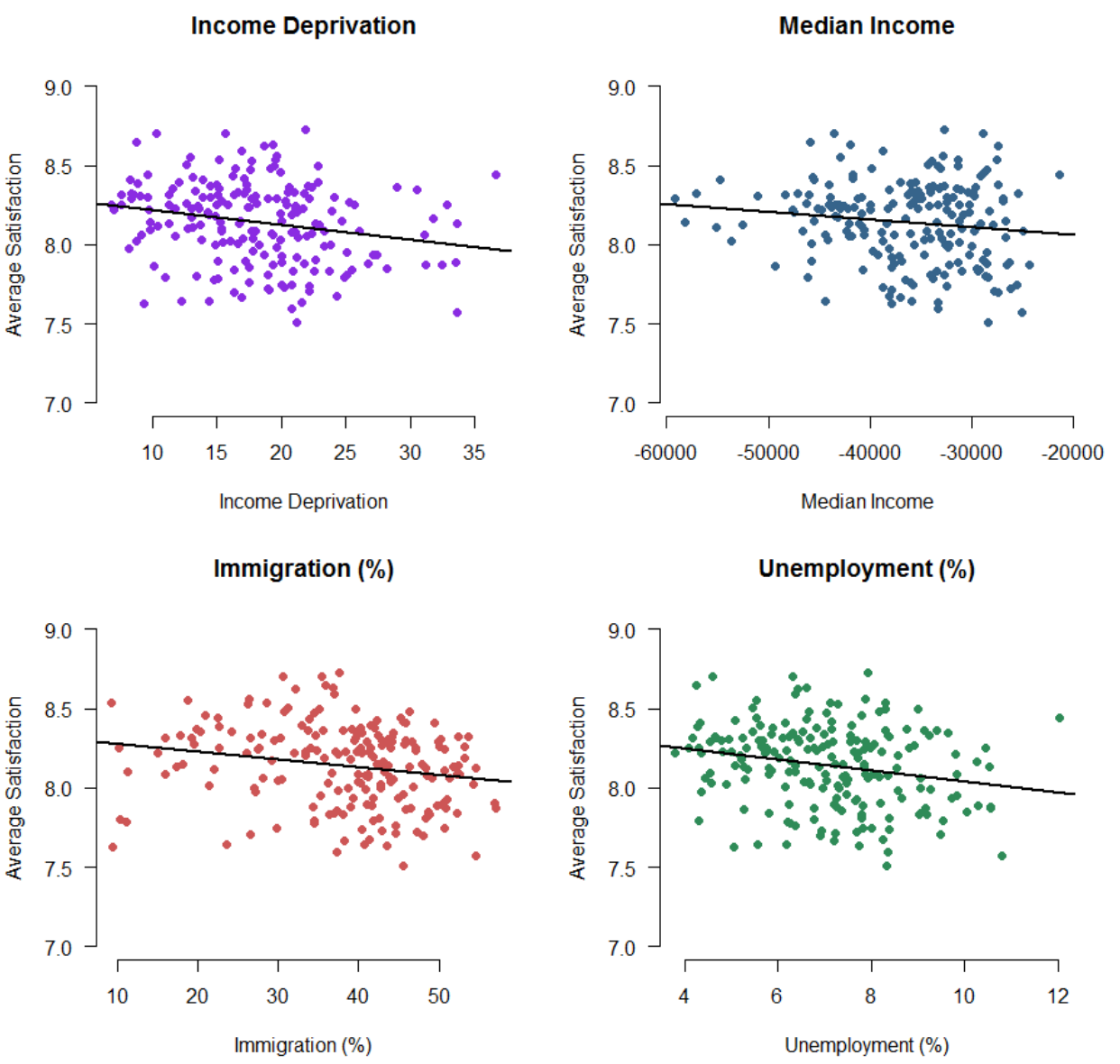

FIGURE 3 Plot of the relationship between average overall bus route satisfaction and each variable of the social deprivation indicator (statistical significance observed at the $99 \%$ 9 confidence level for income deprivation, immigration and unemployment, while median income was significant at the $90 \%$ confidence level). 
1 Table 1 reports the mean value of satisfaction among every route serving certain socioeconomic

2 neighborhoods.

4 Table 1: Average score for survey questions among different groups

\begin{tabular}{lccccccc}
\hline Survey Question & \multicolumn{7}{c}{ Social Deprivation Quintile } \\
\hline & Least deprived (1) & \multicolumn{1}{c}{ Most deprived (5) } \\
& $\mathbf{1}$ & $\mathbf{2}$ & $\mathbf{3}$ & $\mathbf{4}$ & $\mathbf{5}$ & Average \\
\hline Satisfaction with bus stop and shelter where you caught your bus & & & \\
Personal safety & 8.4 & 8.4 & 8.4 & 8.3 & 8.3 & 8.3 \\
\hline Information provided & 8 & 8 & 8 & 8 & 8 & 8.0 \\
\hline Freedom from litter & 8.2 & 8 & 8 & 7.9 & 7.8 & 8.0 \\
\hline Cleanliness & 8.3 & 8.3 & 8.2 & 8.1 & 8.1 & 8.2 \\
\hline State of repair & 8.4 & 8.3 & 8.3 & 8.2 & 8.2 & 8.3 \\
\hline Satisfaction with the bus you have just travelled on & 8.5 & 8.4 & 8.4 & 8.3 & 8.4 & 8.4 \\
\hline Information provided (exterior of bus) & 8.3 & 8.2 & 8.1 & 8.1 & 8.1 & 8.2 \\
\hline Information provided (interior of bus) & 8.3 & 8.2 & 8.3 \\
\hline Cleanliness (exterior) & 8.4 & 8.4 & 8.3 & 8.2 & 8.2 & 7.9 \\
\hline Cleanliness (interior) & 8.2 & 8 & 7.9 & 7.8 & 7.7 & 8.4 \\
\hline State of repair (bus exterior) & 8.5 & 8.4 & 8.4 & 8.3 & 8.3 & 8.2 \\
\hline State of repair (bus interior) & 8.4 & 8.3 & 8.2 & 8.1 & 8.1 & 8.1 \\
\hline Comfort & 8.2 & 8.1 & 8.1 & 8.1 & 8 & 8.6 \\
\hline Personal safety & 8.7 & 8.6 & 8.6 & 8.5 & 8.5 & 8.5 \\
\hline Driver's behaviour and attitude & 8.6 & 8.5 & 8.5 & 8.4 & 8.5 & 7.9 \\
\hline Length of time waited for the bus & 8 & 7.9 & 7.9 & 7.8 & 7.7 & 8.3 \\
\hline Length of journey time & 8.4 & 8.3 & 8.3 & 8.2 & 8.2 & 8.5 \\
\hline Ease of getting on and off the bus & 8.6 & 8.6 & 8.5 & 8.4 & 8.4 & 7.9 \\
\hline Level of crowding & 8.1 & 8 & 7.9 & 7.9 & 7.7 & 8.1 \\
\hline Smoothness and freedom from jolting & 8.2 & 8.1 & 8.1 & 8 & 8.1 & 7.7 \\
\hline Reliability* & 7.8 & 7.9 & 7.8 & 7.8 & 7.7 \\
\hline *Respondents were asked to reflect on this and recent journeys & on that bus & & & & \\
\hline
\end{tabular}

\section{Factor Analysis}

In addition to evaluating overall customer satisfaction, other survey questions related to different attributes of the service, were considered in this analysis, such as comfort, safety, service reliability and travel time. Given the volume of questions related to satisfaction of various service characteristics that were asked, and the relatively high correlation among the responses, Principle Component Analysis (PCA) was used to derive factors of related responses, which was a similar approach to previous studies using large survey data (Tyrinopoulos and Antoniou 2008, Figler, Sriraj et al. 2011, Verbich and El-Geneidy 2016). By means of the PCA, three component factors were identified from 17,516 survey responses. Table 1 presents the three factor components, including the questions that comprise each component, the factor loadings of each question and the given name of each factor component. Similar to the interpretation of a correlation coefficient, 
1 a factor loading that is closer in value to 1 indicates a stronger relationship between the attribute

2 and the factor variable as a whole (Figler, Sriraj et al. 2011).

The first component deals with satisfaction questions related to the quality and cleanliness of the bus (interior and exterior of bus) and on-board comfort and safety. The second component focuses on satisfaction with waiting and journey time, reliability, crowding and driver's behaviour. The third component pertains to the appearance, safety and information provided at the bus stop and/or shelter.

TABLE 1 Results from the Principle Component Analysis

\section{Component}

\section{Survey Question}

Loading

.738

Satisfaction with the state of repair of the inside of the bus

Satisfaction with the cleanliness and freedom from litter inside the bus

.729

Satisfaction with the cleanliness and freedom from graffiti of the outside of the bus

1. Satisfaction with the on-board experience and interior of the bus

Satisfaction with the information provided on the outside of the bus

.637

Satisfaction with your level of comfort inside the bus

.589

Satisfaction with your personal safety during the bus journey .576

Satisfaction with the notices and other information provided inside the bus .560

Satisfaction with ease of getting on and off the bus

Satisfaction with length of time waited .518 .715

Satisfaction with reliability of present and recent trips on

2. Satisfaction with the performance and service quality of the trip current bus route

Satisfaction with the length of time for the bus journey

.654

Satisfaction with the level of crowding inside the bus

Satisfaction with the smoothness and freedom from jolting during your journey .562

Satisfaction with driver's behaviour and attitude towards you

Satisfaction with the cleanliness and freedom from litter at the stop/shelter

Satisfaction with the freedom from graffiti at the

3. Satisfaction with the bus stop and shelter stop/shelter .732

Satisfaction with the state of repair at the stop/shelter .693

Satisfaction with personal safety at the stop/shelter .589

Satisfaction with the information provided at the Stop/shelter

Figure 4 displays the relationship between social deprivation and average satisfaction with each factor component, at the route level. Statistically significant and negative relationships are observed between social deprivation and satisfaction with the on-board experience and interior of 
the bus (Factor 1) and satisfaction with the bus stop and shelter (Factor 3), at the $99 \%$ confidence level. However, no significant relationship is observed between satisfaction with the performance and service quality of the trip (Factor 2) and social deprivation. Put simply, the discrepancy of route-level satisfaction appears to be attributed to lower levels of satisfaction with service features related to the vehicles and bus stop facilities in more socially deprived neighbourhoods. Next, we further explore this relationship, by disaggregating users' satisfaction and evaluating individual responses regarding satisfaction of the route the user took.
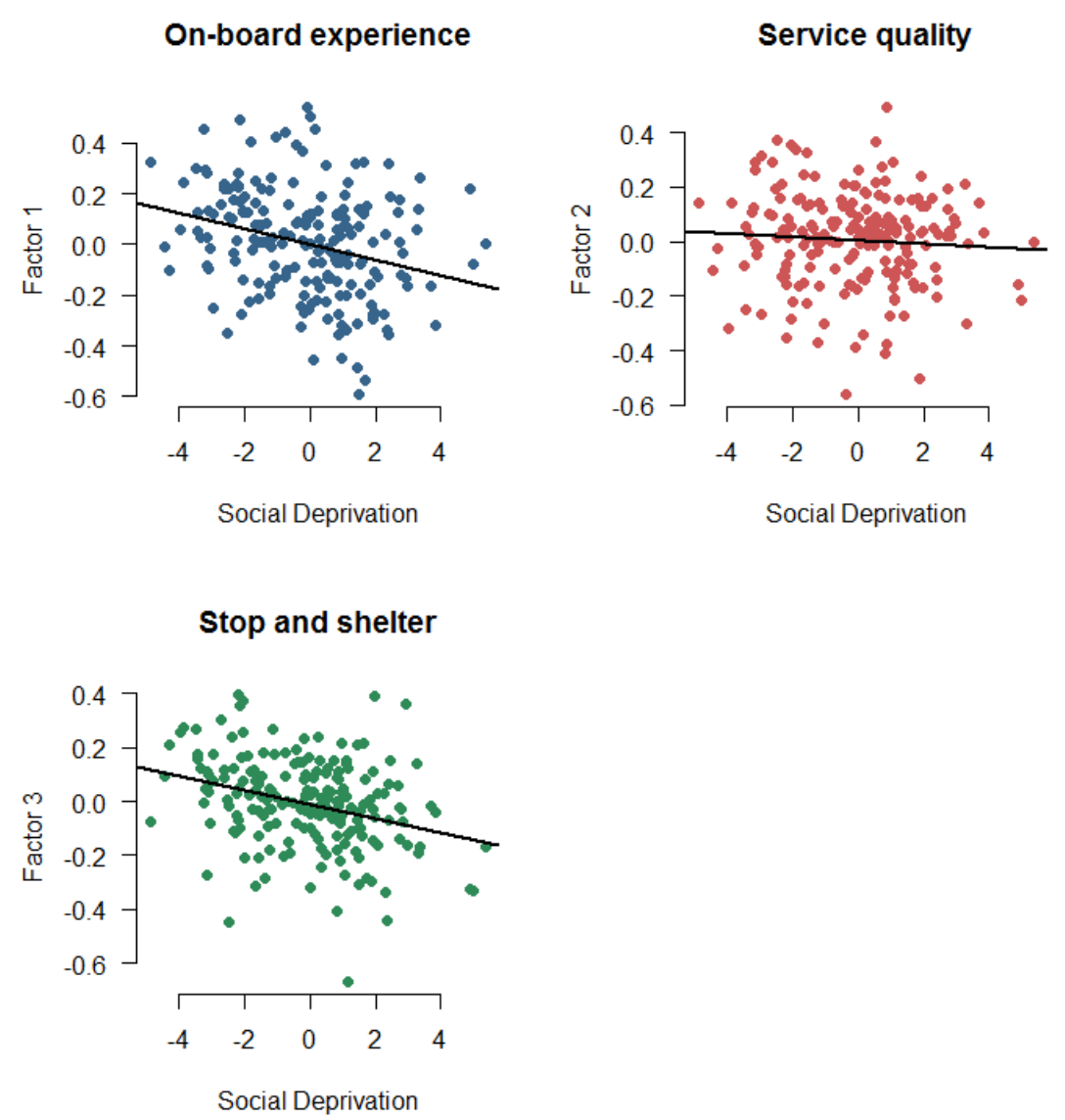

FIGURE 4 Scatterplots of the relationship between the level of social deprivation of each bus route and each factor component.

\section{Individual Level Analysis}

Individual satisfaction responses were evaluated to more accurately estimate variation in customer satisfaction levels across the bus network. This resulted in 17,516 unique responses from 461 bus routes. To evaluate variation among user satisfaction of each route, we segmented the routes by quintiles based on the social deprivation indicator of the route the user alighted from, where each quintile contains $20 \%$ of the bus routes in the data. Using the segmented responses by deprivation quintile, averages of overall satisfaction and satisfaction with each factor component were computed, and are presented in Table 2 . The differences in the mean values between quintiles were evaluated to determine statistical significance of observed differences and are presented in Table 3. The level of significance between means was calculated using a one-way ANOVA with post

23 hoc Tukey test. 
The average overall satisfaction of all routes is 8.13 out of 10 , however by examining the mean values of each social deprivation quintile, average overall satisfaction is highest among routes in the least socially deprived quintiles. Noting the statistically significant differences, the mean overall satisfaction of quintile 5 (the most deprived) is lower than quintile 1 (the least deprived) by 0.19 . Furthermore, quintile 5 is 0.13 and 0.12 lower than quintiles 2 and 3 , respectively.

TABLE 2 Average Values of Overall Satisfaction and Factor Components by Social Deprivation Quintile

\begin{tabular}{|c|c|c|c|c|c|c|c|}
\hline \multirow[b]{2}{*}{ Variable } & \multirow[b]{2}{*}{ Variable Description } & \multirow[b]{2}{*}{ Average } & \multicolumn{5}{|c|}{ Least Deprived (1) -- Most Deprived (5) } \\
\hline & & & 1 & 2 & 3 & 4 & 5 \\
\hline $\begin{array}{l}\text { Average overall } \\
\text { bus route } \\
\text { satisfaction }\end{array}$ & $\begin{array}{l}\text { Satisfaction with the } \\
\text { overall service you } \\
\text { experienced today }\end{array}$ & 8.131 & 8.233 & 8.165 & 8.160 & 8.088 & 8.039 \\
\hline Factor 1 & $\begin{array}{l}\text { Satisfaction with the } \\
\text { on-board experience } \\
\text { and interior of the bus }\end{array}$ & 0.001 & 0.114 & 0.037 & 0.012 & -0.060 & -0.060 \\
\hline Factor 2 & $\begin{array}{l}\text { Satisfaction with the } \\
\text { performance and } \\
\text { service quality of the } \\
\text { trip }\end{array}$ & 0.000 & 0.042 & 0.005 & -0.008 & -0.013 & -0.007 \\
\hline Factor 3 & $\begin{array}{l}\text { Satisfaction with the } \\
\text { bus stop and shelter }\end{array}$ & 0.000 & 0.059 & 0.036 & 0.006 & -0.033 & -0.049 \\
\hline
\end{tabular}

Table 3 Examining Differences in the Mean Values Among Social Deprivation Quintiles

12 Using the Tukey Test

\begin{tabular}{|c|c|c|c|c|c|c|c|c|}
\hline \multirow{2}{*}{$\begin{array}{l}\text { Deprivation } \\
\text { Quintiles }\end{array}$} & \multicolumn{2}{|c|}{$\begin{array}{c}\text { Average overall } \\
\text { satisfaction }\end{array}$} & \multicolumn{2}{|c|}{$\begin{array}{l}\text { Satisfaction with } \\
\text { the on-board } \\
\text { experience and } \\
\text { interior of the bus }\end{array}$} & \multicolumn{2}{|c|}{$\begin{array}{c}\text { Satisfaction with } \\
\text { the performance } \\
\text { and service quality } \\
\text { of the trip }\end{array}$} & \multicolumn{2}{|c|}{$\begin{array}{l}\text { Satisfaction with } \\
\text { the bus stop and } \\
\text { shelter }\end{array}$} \\
\hline & Difference & P-Value & Difference & P-Value & Difference & P-Value & ence & P-Value \\
\hline $5-1$ & $-0.194 * *$ & 0.000 & -0.17 & 0.000 & -0.049 & 0.381 & -0. & 0.001 \\
\hline $5-2$ & $-0.126 *$ & 0.014 & $-0.097 * *$ & 0.000 & -0.012 & 0.9 & -0. & 0.003 \\
\hline $5-3$ & $-0.121 *$ & 0.016 & $-0.071 *$ & 0.017 & 0.001 & 1.00 & -0.055 & 0.118 \\
\hline $5-4$ & -0.049 & 0.732 & 0.000 & 1.000 & 0.006 & 0.999 & -0.016 & 0.958 \\
\hline
\end{tabular}

** Significant difference at $99 \%$ confidence level

*Significant difference at the $95 \%$ confidence level

With regards to the relationship between satisfaction with each factor and social deprivation, we find that factors 1 and 3 (on-board experience and interior of the bus and quality of the bus stop and shelter) react similarly to overall satisfaction. Differences among mean values for satisfaction with the on-board experience and interior of the bus revealed statistically significant lower mean values of $0.17,0.10$ and 0.07 in quintiles 1,2 and 3 compared to quintile

21 5. Similarly, comparing mean values for satisfaction with the bus stop and shelter among quintiles 
to quintile 5 revealed statistically significant lower mean values of quintiles 1 and 2, which on average were lower by 0.11 and 0.09 . These findings potentially suggest a discrepancy in the quality of buses operating in more deprived neighbourhoods, as well as inequalities in the maintenance or state of repair of stops and shelters in more deprived areas. Satisfaction with the performance and service quality of the trip however, revealed no differences among the social deprivation quintiles. The findings presented so far seem to suggest that the lower assessment of overall satisfaction is observed in more socially deprived quintiles and can be attributed to the lower satisfaction of service characteristics related to the on-board experience and interior of the bus and the satisfaction with the bus stops and shelters.

\section{Multi-level Regression Models}

Multi-level regression modeling was employed to analyze how customer satisfaction varies as a function of various route characteristics and neighbourhood SES. A multi-level approach was chosen for this analysis, since an individual's satisfaction of each bus route is of interest, multilevel modeling allows us to control and isolate the average variation in satisfaction between routes. In other words, the multi-level model allows us to differentiate between the variation that is caused within the route from the variation between routes. A likelihood ratio test (LR test) is used to assess the appropriateness of the use of multi-level regression for the analysis. The LR test was statistically significant, which validated the importance of considering that satisfaction varies across different routes.

Four multi-level regression models were used. First, a logit model was developed to model overall satisfaction using a binary variable of whether an individual was satisfied with their trip. A user was considered as satisfied with their trip, if they rated the overall service as a seven and above out of ten, while six and below was considered dissatisfied with the overall trip. This cutoff for satisfaction was selected as interviewers were instructed to ask follow-up questions to determine the reasons for a respondent's dissatisfaction. The remaining three models were estimated using a linear multi-level mixed-effects model, to predict satisfaction with each factor component. The four models include the same control variables, which are presented and described in Table 4.

Table 5 presents the odds ratios and 95\% confidence intervals for the multi-level logit model, which determines the probability of an individual being satisfied overall with their bus trip. As expected, there was a statistically significant difference in overall satisfaction between the most and least socially deprived quintiles. The odds of users of a bus route in the most deprived quintile being satisfied overall with the service decreases by $21 \%$ compared to quintile 1 (least deprived group), when controlling for other variables. This finding indicates that after controlling for relevant characteristics related to the bus trip as well as personal characteristics, passengers' using bus routes operating in an area with high social deprivation are more likely to be dissatisfied with their trip compared to those using routes going through the least deprived areas.

Additional variables were found to play a role in predicting whether an individual is satisfied with their bus trip. Namely, the odds of an individual being satisfied with their bus trip are predicted to be 2.29 times higher for an individual who was seated during their trip compared to users who had to stand. Furthermore, individuals who made a short trip (under 30 minutes) are predicted to be 2.29 times more likely to be satisfied with their trip overall than individuals whose trip was longer than 60 minutes, while keeping all other variables constant at their mean. Finally, the odds of an individual being satisfied with their trip during peak hours are predicted to be $17 \%$ lower than individuals whose trip occurred during an off-peak time. These variables behave in 
1 line with a previous study of determinants of satisfaction among bus users (Beirão and Cabral 2 2007). 
TABLE 4 Description of Multi-level Model Variables

\begin{tabular}{|c|c|}
\hline Variable Name & Description \\
\hline \multicolumn{2}{|l|}{ Model Dependent Variables } \\
\hline Model 1: Overall Satisfaction & $\begin{array}{l}\text { Dummy variable that equals } 1 \text { if a rider stated their satisfaction with the overall service was } 7 \text { or above, } \\
\text { otherwise } 0 .\end{array}$ \\
\hline $\begin{array}{l}\text { Model 2: Satisfaction with the on-board } \\
\text { experience and interior of the bus }\end{array}$ & Factor loading for satisfaction with the on-board experience and interior of the bus \\
\hline $\begin{array}{l}\text { Model 3: Satisfaction with the } \\
\text { performance and service quality of the } \\
\text { trip }\end{array}$ & Factor loading for satisfaction with the performance and service quality of the trip \\
\hline $\begin{array}{l}\text { Model 4: Satisfaction with the bus stop } \\
\text { and shelter }\end{array}$ & Factor loading for satisfaction with the bus stop and shelter \\
\hline \multicolumn{2}{|l|}{ Social Deprivation Indicator } \\
\hline Quantile 5 & Dummy variable of 1 if route is segmented in quantile 5 (20\% most socially deprived routes $), 0$ otherwise. \\
\hline Quantile 4 & Dummy variable of 1 if route is segmented in quantile 4,0 otherwise. \\
\hline Quantile 3 & Dummy variable of 1 if route is segmented in quantile 3,0 otherwise. \\
\hline Quantile 2 & Dummy variable of 1 if route is segmented in quantile 2,0 otherwise. \\
\hline Quantile 1 & Dummy variable of 1 if route is segmented in quantile 1 ( $20 \%$ least socially deprived routes $), 0$ otherwise. \\
\hline \multicolumn{2}{|l|}{ Bus Trip Characteristics } \\
\hline Seat (Dummy) & Dummy variable that equals 1 if a rider had a seat, and 0 otherwise. \\
\hline Short trip $(<30$ minutes $)$ & Dummy variable that equals 1 if a users' trip took less than 30 minutes, and 0 otherwise. \\
\hline Medium trip (30-60 mins) & Dummy variable that equals 1 if a users' trip took between 30-60 minutes, and 0 otherwise. \\
\hline Long trip (>60 mins) & Dummy variable that equals 1 if a users' trip took longer than 60 minutes, and 0 otherwise. \\
\hline Peak hour trip & $\begin{array}{l}\text { Dummy variable that equals } 1 \text { if a users' trip took place during a peak hour (6:30 to 9:29 and 16:00 to } \\
18: 59) \text {, and } 0 \text { otherwise. }\end{array}$ \\
\hline Route length $(\mathrm{km})$ & The length of the route in $\mathrm{km}$. \\
\hline \multicolumn{2}{|l|}{ Personal Characteristics } \\
\hline Sex & Dummy variable that equals 1 if a user identified their sex as being male, and 0 otherwise. \\
\hline Age & Categorical age of a user. \\
\hline White & Dummy variable that equals 1 if a user identified their ethnicity as being white, and 0 otherwise. \\
\hline Asian & Dummy variable that equals 1 if a user identified their ethnicity as being Asian, and 0 otherwise. \\
\hline Black & Dummy variable that equals 1 if a user identified their ethnicity as being black, and 0 otherwise. \\
\hline
\end{tabular}


TABLE 5 Multi-level Logistic Regression of Overall Satisfaction ( 7 and above)

\begin{tabular}{lccc}
\hline & Odds Ratio & 95\% Confidence interval & 2 \\
\hline Social Deprivation Quintile & & & \\
\hline $\begin{array}{l}\text { Quintile 5 (Top 20\% } \\
\text { socially deprived) }\end{array}$ & $\mathbf{0 . 7 9 *}$ & 0.65 & 0.96 \\
\hline Quintile 4 & 0.90 & 0.74 & 1.08 \\
\hline $\begin{array}{l}\text { Quintile 3 } \\
\text { Quintile 2 }\end{array}$ & 0.95 & 0.79 & 1.14 \\
\hline $\begin{array}{l}\text { (ref }=\text { Quintile 1) } \\
\text { Bus Trip Characteristics }\end{array}$ & 0.94 & 0.78 & 1.14 \\
\hline Seat (Dummy) & & & \\
\hline Short trip (<30 minutes) & $\mathbf{2 . 2 9 * *}$ & 1.96 & 2.67 \\
\hline $\begin{array}{l}\text { Medium trip (30-60 mins) } \\
\text { (ref }=\text { Long trip }(>60 \text { mins) })\end{array}$ & 0.95 & 0.66 & 3.27 \\
\hline Pea hour & & 1.38 \\
\hline
\end{tabular}

Peak hour trip

(reference $=$ non-peak

trip)

\begin{tabular}{rrr}
$\mathbf{0 . 8 3} * *$ & 0.76 & 0.91 \\
\hline
\end{tabular}

Route length $(\mathrm{km})$

1.0

\section{Personal Characteristics}

Sex $(r e f=$ female $)$

Age

1.10

1.00

1.21

Ethnicity $(r e f=$ mixed $)$

White

1.02

0.98

1.06

Asian

1.18

0.88

1.58

Black

0.77

0.58

1.04

Random-effects parameters

0.78

0.58

1.05

Sd (constant)

Estimate

95\% Conf. int

$\mathrm{Sd}$ (residual)

0.0084

0.0048 .0015

Intraclass correlation

0.98

0.96

1.00

** Statistically significant at the $99 \%$ confidence level

* Statistically significant at the $95 \%$ confidence level

$\mathrm{N}=17,516$

The intra-class correlation coefficient (ICC) of this logit model showed that approximately $1.2 \%$ of the total variance of overall satisfaction was explained from variation between the bus routes. The low ICC coefficient indicates that the variation observed among satisfaction is not resulting from high correlation between routes, rather it is explained by the independent variables included in the model.

Table 6 presents the results of the three multi-level linear models of each factor component (groups of satisfaction questions). Regarding the first model evaluating satisfaction with the experience and ride quality, we see that the three most socially deprived quintiles are least likely to be satisfied with the on-board experience and interior of the bus compared to quintile 1, when controlling for other variables. Interestingly, the only other variables with statistical significance in this model were the variables describing whether an individuals had a 
seat during their trip, and an individual's ethnicity. Individuals with a seat during their bus trip are predicted to be more satisfied with their experience and quality of the bus. This model also revealed that in comparison to an individual of mixed ethnicity, a rider who is Asian is predicted to have lower satisfaction with the on-board experience and interior of the bus when compared to a rider of mixed ethnicity.

Next, we consider satisfaction with the performance and service quality of the trip. We find that neighbourhood social deprivation is not a significant predictor of an individual's satisfaction with service features related to ride quality, when controlling for other variables. This finding indicates that individuals assessed the characteristics of their trip related to the driver behaviour, level of crowding, length of time waited, journey time and reliability uniformly despite level the of social deprivation of the neighbourhood of which the bus trip occurred. Rather, satisfaction with the performance and service quality of the trip was estimated to be higher among individuals who had a seat during their trip as well as individuals whose trip duration was under 30 minutes. Furthermore, passengers are expected to be less satisfied with the service quality during peak hours. This finding warrants additional attention to the quality of service during peak times to better serve passengers during peak hour trips. Lastly, in regards to personal characteristics, the model reveals a higher satisfaction value with the performance and service quality of the trip for each increase in age interval. Also, as seen in the previous model, individuals of Asian ethnicity were found to be less satisfied with characteristics of the performance and service quality of the trip, when compared to an individual of mixed ethnicity. The predicted lower satisfaction among Asian riders may potentially be indicative of differences in expectations among service quality between different ethnicities.

Results of the final regression model, reveals statistically significant differences between social deprivation quintiles and satisfaction with the bus stop and shelter. Compared to bus routes operating in the least socially deprived regions of London, lower levels of satisfaction with the bus stop and shelter are expected in bus routes serving the two most socially deprived quintiles, when other variables are controlled for. Similar to the result for the satisfaction with the on-board experience and interior of the bus, the statistically lower satisfaction with these factor components likely explains the discrepancy of quality with buses and bus stop facilities in areas of higher social deprivation. An unexpected negative association between whether an individual had a seat during their trip and the length of the trip was observed in this model. Contrary to the other models and the hypothesized direction of the relationship, an individual who had a seat during their trip is likely to be less satisfied with the bus stop and shelter, and individuals whose trip was under 60 minutes were less satisfied than an individual whose trip duration was over 60 minutes. Furthermore, satisfaction with the bus stop and shelter is predicted to be lower for longer bus routes. Finally, individuals who stated their ethnicity as white were likely to be more satisfied with the bus stop facilities than individuals who stated their ethnicity as mixed.

The intra-class correlation coefficients (ICC) of these multi-level linear models show that approximately $2.1 \%$ of the total variance of satisfaction with the on-board experience and interior of the bus, $1.6 \% \%$ of the total variance of satisfaction with performance and service quality of the trip, and $0.8 \%$ of the total variance of satisfaction with the bus stop and shelter was explained from variation between the bus routes. Similar to the first multi-level model, the low ICC coefficient indicates that variation among satisfaction is explained by the predictor variables in the model. 
Table 6 Multi-Level Linear Regression with Each Factor Variable as the Dependent Variable

\begin{tabular}{|c|c|c|c|c|c|c|c|c|c|}
\hline & \multicolumn{3}{|c|}{$\begin{array}{c}\text { FACTOR } 1 \text { - Satisfaction with } \\
\text { the on-board experience and } \\
\text { interior of the bus }\end{array}$} & \multicolumn{3}{|c|}{$\begin{array}{c}\text { FACTOR } 2 \text { - Satisfaction with } \\
\text { the performance and service } \\
\text { quality of the trip }\end{array}$} & \multicolumn{3}{|c|}{$\begin{array}{c}\text { FACTOR } 3 \text { - Satisfaction with } \\
\text { the bus stop and shelter }\end{array}$} \\
\hline & Coefficient & $95 \%$ & nf. int & Coefficient & $95 \%$ & If int. & Coefficient & $95 \%$ & ff. int \\
\hline \multicolumn{10}{|c|}{ Social Deprivation Quintile } \\
\hline $\begin{array}{l}\text { Quintile } 5 \text { (Top 20\% } \\
\text { socially deprived) }\end{array}$ & $-0.14 * *$ & -0.21 & -0.06 & -0.02 & -0.10 & 0.05 & $-0.08 *$ & -0.14 & -0.01 \\
\hline Quintile 4 & $-0.15 * *$ & -0.22 & -0.08 & -0.04 & -0.11 & 0.03 & $-0.07 *$ & -0.13 & -0.01 \\
\hline Quintile 3 & $-0.11 *$ & -0.18 & -0.03 & -0.03 & -0.10 & 0.04 & -0.04 & -0.10 & 0.03 \\
\hline $\begin{array}{l}\text { Quintile } 2 \\
\text { (ref= Quintile 1) }\end{array}$ & -0.06 & -0.13 & 0.02 & -0.03 & -0.10 & 0.04 & -0.02 & 0.09 & 0.04 \\
\hline \multicolumn{10}{|l|}{ Bus Trip Characteristics } \\
\hline Seat (Dummy) & $0.19 * *$ & 0.13 & 0.25 & $0.43 * *$ & 0.37 & 0.49 & $-0.09 * *$ & -0.15 & -0.03 \\
\hline Short trip (<30 mins) & 0.06 & -0.08 & 0.20 & $0.44 * *$ & 0.30 & 0.58 & $-0.21 * *$ & -0.35 & -0.06 \\
\hline $\begin{array}{l}\text { Medium trip ( } 30-60 \text { mins) } \\
\text { (ref= Long trip) }\end{array}$ & 0.03 & -0.12 & 0.18 & 0.05 & -0.10 & 0.20 & $-0.23 * *$ & -0.38 & -0.08 \\
\hline $\begin{array}{l}\text { Peak hour trip (ref=non- } \\
\text { peak) }\end{array}$ & 0.02 & -0.01 & 0.05 & $-0.13 * *$ & -0.16 & -0.10 & -0.01 & -0.04 & 0.02 \\
\hline Route length $(\mathrm{km})$ & 0.00 & -0.01 & 0.01 & 0.00 & 0.00 & 0.01 & $-0.01 *$ & -0.01 & 0.00 \\
\hline \multicolumn{10}{|l|}{ Personal Characteristics } \\
\hline Sex $(r e f=$ female $)$ & 0.00 & -0.03 & 0.03 & -0.01 & -0.04 & 0.02 & 0.01 & -0.02 & 0.04 \\
\hline Age & 0.00 & -0.01 & 0.01 & $0.03 * *$ & 0.02 & 0.04 & 0.00 & -0.01 & 0.02 \\
\hline Ethnicity (ref $=$ mixed $)$ & & & & & -0.12 & 0.07 & & 0.09 & 0.28 \\
\hline White & 0.06 & -0.03 & 0.15 & -0.02 & -0.24 & -0.05 & $0.19 * *$ & -0.06 & 0.13 \\
\hline Asian & $-0.10 *$ & -0.19 & 0.00 & $-0.15 * *$ & -0.13 & 0.06 & 0.03 & -0.05 & 0.15 \\
\hline Black & -0.07 & -0.17 & 0.02 & -0.03 & -0.10 & 0.05 & 0.05 & -0.14 & -0.01 \\
\hline \multicolumn{10}{|c|}{ Random-effects parameters } \\
\hline $\mathrm{Sd}($ constant) & 0.021 & 0.016 & 0.029 & 0.16 & 0.01 & 0.23 & 0.01 & 0.00 & 0.15 \\
\hline Sd (residual) & 0.97 & 0.95 & 0.99 & 0.95 & 0.93 & 0.97 & 0.98 & 0.96 & 1.00 \\
\hline Intraclass correlation & & $2.1 \%$ & & & $1.6 \%$ & & & $0.8 \%$ & \\
\hline \multicolumn{10}{|c|}{$* *$ Statistically significant at the $99 \%$ confidence level } \\
\hline
\end{tabular}




\section{DISCUSSION AND CONCLUSIONS}

This study has presented a new method for evaluating customer satisfaction survey data. Using a spatial analytical approach, passengers' perception of service was evaluated across the network of London Buses to determine whether passengers perceived the same quality of service across neighbourhood levels of SES. By segmenting routes according to level of neighbourhood social deprivation, the findings indicate that mean values of overall satisfaction were highest in the least deprived neighbourhoods and lowest in areas with higher social deprivation. The observed discrepancies in customer perceptions of service in lower SES areas, appears to be explained mostly by lower satisfaction with service features related to an individual's experience and perception of the quality of facilities and vehicles operating in these areas.

The multi-level regression model of overall satisfaction employed in this study found that the level of SES is a statistically significant predictor of whether an individual was satisfied with their most recent trip, after controlling for characteristics of the bus trip and personal characteristics. In a trial to better understand the reasoning for such lower level of satisfaction we modeled the level of satisfaction with different service components. Modeling satisfaction with each factor component revealed that lower SES neighbourhoods were predicted to be less satisfied with the factors comprising attributes related to the on-board experience and interior of the bus, and the bus stop and/or shelter, while controlling for other factors. However, the model results of the factor component pertaining to the performance and service quality of the trip revealed no significant differences among quintile groups, indicating a consistent assessment of service attributes such as journey time, waiting time, reliability, level of crowding and smoothness of the trip across neighbourhood SES levels. Most transit agencies regard reliability as a key factor in building customer satisfaction (Diab, Badami et al. 2015), largely since growth in public transport patronage can result from service reliability improvements, while it can decay due to unreliable service (Bates, Polak et al. 2001, Noland and Polak 2002). However, transit riders generally perceive out-of-vehicle travel time (i.e. transferring and waiting for vehicles) to be more onerous than time spent in-vehicle (Guo and Wilson 2004, Stradling, Anable et al. 2007), and accordingly, impact satisfaction. For that reason, transport agencies often aim to design stops and shelters with various amenities to reduce the burden of waiting and transferring (Iseki and Taylor 2010). Therefore, it is important not to overlook customers' perceptions of service related to waiting conditions. Moreover, individuals with positive perceptions of safety, comfort, appearance and convenience of bus service have been shown to be more loyal customers (Figler, Sriraj et al. 2011). Discrepancies in service features related to the bus vehicles and waiting conditions must be addressed for greater satisfaction and retention of public transport users in lower SES neighbourhoods, especially because an individual's experience with public transport largely determines their transport behavior (Thøgersen 2006).

The fact that London Buses are operated under contracts with various private operators, appears to be an effective means of providing a reliable transit service across different neighbourhood SES levels. This is because customers across varying levels of SES were equally satisfied with service attributes related to the reliability and on-time performance of their trip, which are service attributes closely monitored through contract performance standards. The dilemma presented by these findings is that quality standards of service features related to vehicles and stop facilities are not incorporated into minimum performance standards set within contracts with private operators. Accordingly, performance indicators specific to the state of repair and cleanliness of vehicles should be adopted in future contract to ensure a high quality service for all 
1 SES. Furthermore, London Buses should assess the state of repair, information and cleanliness of 2 bus stops and shelters across the network, as these facilities are managed by London Buses.

3 This study provides evidence of the success of delivering quality public transport service 4 under the regime of public transport contracts. However, to increase customer satisfaction and 5 loyalty and retain passengers, such as transit captive riders in areas of higher social deprivation, 6 more attention to the quality of buses as well as bus stops and shelters provided across the network 7 is required. At a time when bus contracting is receiving interest around the world, the findings 8 from this research show the success of this contracting method as it appears to aid in the provision 9 of a consistent level of service, as it is reflected in the satisfaction with service quality questions, 10 across all areas regardless of neighbourhood SES. Furthermore, this study highlights the 11 importance of including cleanliness and bus internal quality as performance indicators when 12 contracting bus services, to ensure that all customers receive the same quality of service in the 13 region regardless of their SES, in addition to other widely used reliability measures.

14

15

\section{ACKNOWLEDGMENT}

17 We wish to thank Kathryn Jones, John Barry, and Alex Phillips from TfL for the survey data and 18 support. We would like to the anonymous reviewers for their valuable feedback on the earlier 19 version of the manuscript. This work was supported by research grants from the Natural Sciences

20 and Engineering Research Council of Canada as well as the Social Sciences and Humanities 21 Research Council. 


\section{REFERENCES}

Andreassen, T. (1995). "(Dis) satisfaction with public services: The case of public transportation." Journal of Services Marketing 9(5): 30-41.

Bates, J., J. Polak, P. Jones and A. Cook (2001). "The valuation of reliability for personal travel." Transportation Research Part E: Logistics and Transportation Review 37(2): 191-229.

Begg, D. (2013). World Class? London's Transport: Progress and Future Challenges.

Beirão, G. and J. Cabral (2007). "Understanding attitudes towards public transport and private car: A qualitative study." Transport Policy 14(6): 478-489.

Berry, L., V. Zeithaml and A. Parasuraman (1990). "Five imperatives for improving service quality." Sloan Management.

Bordagaray, M., L. dell'Olio, A. Ibeas and P. Cecín (2014). "Modelling user perception of bus transit quality considering user and service heterogeneity." Transportmetrica A: Transport Science 10(8): 705-721.

Church, A., M. Frost and K. Sullivan (2000). "Transport and social exclusion in London." Transport Policy 7(3): 195-205.

De Ona, J., R. de Oña, L. Eboli and G. Mazzulla (2015). "Heterogeneity in perceptions of service quality among groups of railway passengers." International Journal of Sustainable Transportation 9(8): 612-626.

de Oña, J., R. de Oña, L. Eboli and G. Mazzulla (2013). "Perceived service quality in bus transit service: A structural equation approach." Transport Policy 29: 219-226.

dell'Olio, L., A. Ibeas and P. Cecín (2010). "Modelling user perception of bus transit quality." Transport Policy 17(6): 388-397.

Diab, E., M. Badami and A. El-Geneidy (2015). "Bus transit service reliability and improvement strategies: Integrating the perspectives of passengers and transit agencies in North America." Transport Reviews 35(3): 292-328.

Eboli, L. and G. Mazzulla (2011). "A methodology for evaluating transit service quality based on subjective and objective measures from the passenger's point of view." Transport Policy 18(1): 172-181.

Eboli, L. and G. Mazzulla (2015). "Relationships between rail passengers' satisfaction and service quality: A framework for identifying key service factors." Public Transport 7(2): $185-201$.

El-Geneidy, A., R. Buliung, E. Diab, D. van Lierop, M. Langlois and A. Legrain (2016). "Nonstop equity: Assessing daily intersections between transit accessibility and social disparity across the Greater Toronto and Hamilton Area (GTHA)." Environment and Planning B: Planning and Design 43(3): 540-560.

Figler, S., P. Sriraj, E. Welch and N. Yavuz (2011). "Customer Loyalty and Chicago, Illinois, Transit Authority Buses: Results from 2008 Customer Satisfaction Survey." Transportation Research Record: Journal of the Transportation Research Board(2216): 148-156.

Foth, N., K. Manaugh and A. El-Geneidy (2013). "Towards equitable transit: Examining transit accessibility and social need in Toronto, Canada, 1996-2006." Journal of Transport Geography 29: 1-10.

Friman, M. (2004). "Implementing quality improvements in public transport." Journal of Public transportation 7(4): 3 . 
Friman, M. and M. Fellesson (2009). "Service supply and customer satisfaction in public transportation: the quality paradox." Journal of Public transportation 12(4): 4.

Grigoroudis, E. and Y. Siskos (2009). Customer satisfaction evaluation: Methods for measuring and implementing service quality, Springer Science \& Business Media.

Guo, Z. and N. Wilson (2004). "Assessment of the transfer penalty for transit trips geographic information system-based disaggregate modeling approach." Transportation Research Record 1872: 10-18.

Hamnett, C. (2003). Unequal city: London in the global arena, Psychology Press.

Hansen, W. (1959). "How accessibility shapes land use." Journal of the American Institute of Planners 25(2): 73-76.

Hensher, D., P. Stopher and P. Bullock (2003). "Service quality—developing a service quality index in the provision of commercial bus contracts." Transportation Research Part A: Policy and Practice 37(6): 499-517.

Iseki, H. and B. Taylor (2010). "Style versus service? An analysis of user perceptions of transit stops and stations." Journal of Public Transportation 13(3): 2.

Jones, P. and K. Lucas (2012). "The social consequences of transport decision-making: clarifying concepts, synthesising knowledge and assessing implications." Journal of Transport Geography 21: 4-16.

Legrain, A., R. Buliung and A. El-Geneidy (2016). "Travelling fair: Targeting equitable transit by understanding job location, sectorial concentration, and transit use among low-wage workers." Journal of Transport Geography 53: 1-11.

Martens, K., A. Golub and G. Robinson (2012). "A justice-theoretic approach to the distribution of transportation benefits: Implications for transportation planning practice in the United States." Transportation research part A: policy and practice 46(4): 684-695.

Murray, A. T. and R. Davis (2001). "Equity in regional service provision." Journal of Regional Science 41(4): 557-600.

Noland, R. and J. Polak (2002). "Travel time variability: A review of theoretical and empirical issues." Transport Reviews 22(1): 39-54.

Office for National Statistics. (2015). "Super Output Area (SOA)." from http://www.ons.gov.uk/ons/guide-method/geography/beginner-s-guide/census/superoutput-areas--soas-/index.html.

Olsen, S. O. (2007). "Repurchase loyalty: The role of involvement and satisfaction." Psychology \& Marketing 24(4): 315-341.

Prioni, P. and D. Hensher (2000). "Measuring service quality in scheduled bus services." Journal of Public Transportation 3(2).

Sánchez-Cantalejo, C., R. Ocana-Riola and A. Fernández-Ajuria (2008). "Deprivation index for small areas in Spain." Social Indicators Research 89(2): 259-273.

Stradling, S., J. Anable and M. Carreno (2007). "Performance, importance and user disgruntlement: A six-step method for measuring satisfaction with travel modes." Transportation Research Part A: Policy and Practice 41(1): 98-106.

Thøgersen, J. (2006). "Understanding repetitive travel mode choices in a stable context: A panel study approach." Transportation Research Part A: Policy and Practice 40(8): 621-638.

Townsend, P., P. Phillimore and A. Beattie (1998). Health and deprivation: inequality and the north, Croom Helm, Beckenham, U.K.

Transport for London (2015). London's Bus Contracting and Tendering Process. 
1 Tyrinopoulos, Y. and C. Antoniou (2008). "Public transit user satisfaction: Variability and policy 2 implications." Transport Policy 15(4): 260-272.

3 van Lierop, D. and A. El-Geneidy (2016). "Loyalty in transit: An analysis of bus and rail users in $4 \quad$ two Canadian cities." Research in Transportation Economics.

5 Verbich, D. and A. El-Geneidy (2016). "The pursuit of satisfaction: Variation in satisfaction with 6 bus transit service among different bus users using a large-scale survey from London, $7 \quad$ UK." Transport Policy 47: 64-71.

8 Walker, J. (2008). "Purpose-driven public transport: creating a clear conversation about public

9 transport goals." Journal of transport geography 16(6): 436-442.

$10 \mathrm{Wu}, \mathrm{B}$. and J. Hine (2003). "A PTAL approach to measuring changes in bus service accessibility." Transport Policy 10(4): 307-320. 